\section{A missed opportunity: alcohol excise duty, RSA and trace-back}

\section{Dear Editor}

It is hard to view the changes in alcohol excise duty announced in the recent budget in Ireland in anything other than a highly cynical light. The reductions in excise duty are considerable. The excise duty on beer and cider has been reduced by 12 cent per pint, while the reduction on spirits is 14 cent per half-glass and 60 cent per standard bottle of wine. It should also be noted that alcohol sales in Ireland will also benefit from the $0.5 \%$ reduction in VAT announced in the same budget.

Given Ireland's troubled history and uneasy relationship with alcohol, these moves are alarming. ${ }^{1}$ It seems certain that any Health Impact Assessment (HIA) on this initiative can only predict an adverse health and social outcome. Even if one accepts the economic and tax arguments put forward in relation to sales of alcohol in Northern Ireland the excise reduction manoeuvre appears unbalanced.

Such a move might have been combined with the compulsory introduction of Responsible Serving of Alcohol (RSA) courses for all staff serving alcohol in pubs, restaurants, clubs and off-licences. ${ }^{2}$ This could function rather like the FAS safepass required for work on construction sites.

The reduction in excise duty might equally have been combined with the introduction of a compulsory trace-back initiative covering all sales of alcohol for consumption offsite. Such an initiative was mentioned in the 2006 Sustaining Progress Special Initiative Working Together to Reduce the Harms Caused by Alcohol Misuse. ${ }^{3}$

Both of these measures might have helped to reduce the alarming issue of under-age and binge drinking in Ireland. The second report of the Strategic Task Force on Alcohol noted the need to reduce alcohol consumption by young people given its particular danger to them. ${ }^{4}$ The alcohol industry in Ireland and its apologists routinely mobilise discourses of 'over-regulation' to fend off public health initiatives related to alcohol control. ${ }^{5}$ Attempts to introduce essential regulatory developments such as mandatory RSA courses and traceback will always be resisted by the alcohol industry. If such initiatives had been introduced at the same time as the excise and VAT cuts, they might have met reduced resistance from the alcohol industry and have reduced at least some of the inevitable harm.

Frank Houghton

Irish Centre for Research on Applied Social Studies (ICRASS),

Limerick Institute of Technology

References

1. Anderson P, Baumberg B. Alcohol in Europe. London, Institute of Alcohol Studies, 2006.
2. Graham K. Preventative interventions for on-premise drinking: a promising but under researched area of prevention. Contemporary Drug Problems 2000; 27: 593-668. 3. Working Group on Alcohol Misuse. Sustaining Progress Special Initiative Working Together To Reduce the Harms Caused By Alcohol Misuse. Dublin, Government Publications Office, 2006.

4. Strategic Task Force on Alcohol Second Report. Dublin, Department of Health \& Children, 2004.

5. Grant M. The rush to regulate: Commentary on the EU Report by Peter Anderson. Drugs: education, prevention and policy 2006; 13: 489-492.

\section{New long-stay patients in Irish psychiatric inpatient services}

\section{Dear Editor,}

The paper by A. Daly and D. Walsh entitled "An audit of new long-stay patients in Irish psychiatric inpatient services" in your issue of September 2009, was well written and informative, as one would expect from this source. It described again the evolution of our national mental health policy since 1966. This could be paraphrased in the oft repeated mantra "long stay hospital bad - community treatment good". Whilst the fall in hospital numbers since 1966 has indeed been dramatic the evidence for linking this trend with better national mental health is not immediately clear.

The authors find it "deeply disappointing" that all public psychiatric hospitals are not yet closed.

Even allowing for the fact that the article was submitted before the recent financial crisis I find their projections unrealistic. I also find the penultimate paragraph dealing with the transfer of the remaining patients to generic services where they could be "easily accommodated" to be deeply disturbing. It appears that the implementation of our 46 year old policy must proceed to the bitter end irrespective of patient needs.

It brought to mind a situation very familiar to me in earlier years when children with autism were routinely found to have a mental handicap at age 16 , a discovery linked more to the practice of child psychiatry than to any clinical realities!

In a recent letter to the Irish Times I have drawn attention to the fact that in Worcester, Mass. they have recently embarked on the construction of a 320 bed public psychiatric hospital. This is a remarkable development in a State where de-institutionalisation and inclusion were embraced at a very early stage! I intend to visit this development next spring and further would encourage our College to organise a fact finding tour. Apart from viewing the actual construction it would be interesting to learn what has led to such a remarkable change in policy. Perhaps there are lessons to be learnt?

Michael Mulcahy

Consultant Psychiatrist 73 Merrion Road

Dublin 4.

Note: An unfinished version of this letter appeared erroneously in the December issue The full and correct version appears here. Our apologies to the author. 